\title{
Occupational Health Nursing
}

National Cancer Institute

\section{Source}

National Cancer Institute. Occupational Health Nursing. NCI Thesaurus. Code C16930.

Nursing that focuses on observation and assessment of worker's health status with respect to job tasks and hazards, with a goal to recognize and prevent health effects from hazardous exposures and treat workers' injuries or illnesses. 